\title{
Data-Based Risk Assessment of Cancer Diseases for Life insurance
}

Type of article: Conference abstract

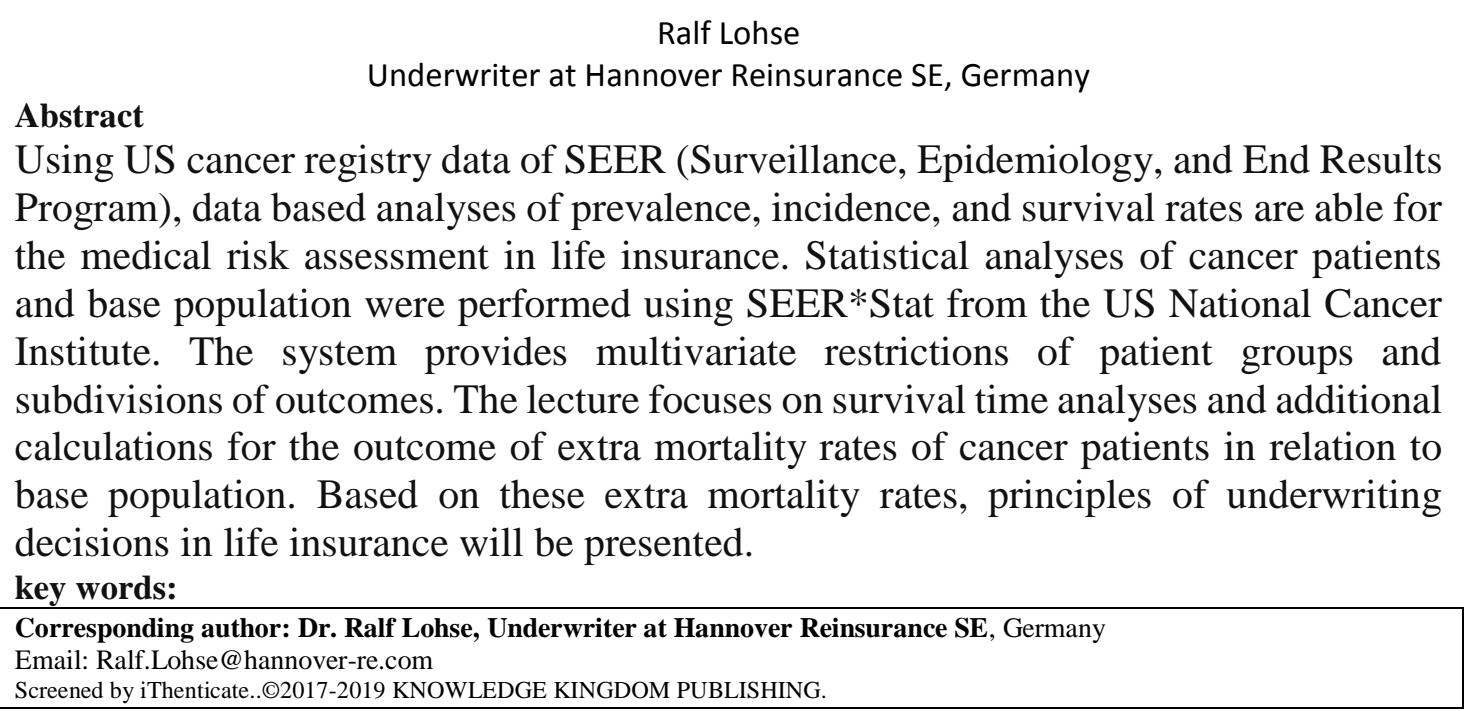

\section{Conflict of interest statement}

This article is an abstract of Keynote presented at the International Congress on Health Sciences and Medical Technologies, Tlemcen, Algeria, December 05-07, 2019 ICHSMT'19.

\section{Authors' biography}

Underwriter at Hannover Reinsurance SE

1987-1992: Diploma economic sciences, Leibniz University Hannover 1997 - 2004: Doctor of economics, Institute for Risk and Insurance, Leibniz University Hannover

1993 - 1997: German Market Department, Hannover Reinsurance SE 1997 - 2000: Actuarial Service Department, Hannover Reinsurance SE Since 2000: Life Risk Assessment, Hannover Reinsurance SE

\section{References}

No references 